\title{
Measles-virus-specific IgG in optic neuritis and in multiple sclerosis after optic neuritis
}

\begin{abstract}
Summary
Measles-virus-specific IgG was measured in the serum of 100 patients who had presented with optic neuritis (ON) during 1960-74. When reviewed 41 of them were found to have developed definite symptoms and signs of multiple sclerosis (MS), their serum containing significantly higher titres of the antibody than sera from either the rest of the patients or a group of normal healthy controls. In a few patients from whom cerebrospinal fluid (CSF) was obtained in the acute phase of $O N$, titres of measles IgG in the serum were higher in those in whom the antibody was detected in the CSF than the serum of patients without CSF antibody.
\end{abstract}

\section{Introduction}

Optic neuritis $(\mathrm{ON})$ is the initial symptom in $10-20^{\circ}{ }_{\circ}$ of patients with multiple sclerosis ${ }^{1}$ (MS), and it is generally accepted that in adults most cases of $\mathrm{ON}$ are a manifestation of MS.' A retrospective study of patients with $\mathrm{ON}$ in Northern Ireland, a high-risk area for MS, showed that there is a $78^{\circ}{ }^{\circ}$, probability of developing MS 15 years later. ${ }^{3}$

Since Adams and Imagawa ${ }^{4}$ first reported a slightly increased titre of antibody to measles virus in the serum of patients with MS compared with controls, this finding has been confirmed by many workers using various techniques, ${ }^{5}$ and a greater prevalence of antibody to measles virus has been detected in the cerebrospinal fluid (CSF) of patients with MS compared with controls. ${ }^{6}$ 7 There have been fewer studies of virus antibodies in the serum and CSF of patients with ON. Nikoskelainen et $a l^{\star}$ studied sera from 77 patients with $\mathrm{ON}$ and compared them with those from 71 healthy controls and 58 patients with neurological disease other than MS. In the 33 patients with $\mathrm{ON}$ of unknown cause, as well as in the whole group of patients with $\mathrm{ON}$, measles antibody titres were higher than in the controls, while there was no difference between the various groups in antibodies against 13 other viruses and Mycoplasma pneumoniae.

Link et $a l^{9}$ showed that out of 41 patients with ON, 21 had oligoclonal IgG in their CSF significantly associated with a pleocytosis; these patients also had about a sevenfold increase in their concentration of measles-virus haemolysis-inhibiting (HLI) antibody when compared with the other patients. Of the 21 patients with oligoclonal IgG in their CSF, 20 also had measles-virus HLI antibodies in their CSF, while only three of the 20 patients without oligoclonal IgG had this abnormality. Oligoclonal IgG has been found in the CSF of $94 \%$ of patients with MS. ${ }^{10}$ Nikoskelainen $e t$ al ${ }^{11}$ found measles antibodies in the $\mathrm{CSF}$ of $62 \%$ of patients with $\mathrm{ON}$ of diverse aetiology, and when

\section{Royal Victoria Hospital, Belfast BT12 6BA}

W M HUTCHINSON, MB, MRCP, clinical research fellow (now registrar, National Hospital for Nervous Diseases, Queen Square, London WC1N 3BG)

Department of Microbiology and Immunobiology, Queen's University of Belfast, Belfast BT12 6BN

MARGARET HAIRE, MD, MRCPATH, senior lecturer patients with $\mathrm{ON}$ of unknown cause were considered $53^{\circ}$, had measles antibodies in the CSF compared with $21_{\%}^{\circ}$ of the control group.

We have shown a significantly higher level of measles-virusspecific IgG in the serum of patients with MS than in patients with other neurological diseases or normal controls, ${ }^{12} 13$ and also that measles-virus-specific IgG is present consistently in the CSF of some $60^{\circ}{ }^{\circ}$ of patients with MS. ${ }^{1+}$ We therefore decided to compare the titres of measles-virus-specific IgG in the serum of patients with a history of ON but without evidence of MS with those in patients in whom ON was the first symptom of MS, and to investigate the presence of measles-virus-specific $\mathrm{IgG}$ in sera and CSF available from patients who presented with an acute attack of $\mathrm{ON}$ of unknown cause.

\section{Patients and methods}

Series $A$-Patients with $\mathrm{ON}$ of unknown cause presenting during 1960-74 were reviewed and the first 100 seen were admitted to the serological study. They were categorised as having had unilateral, recurrent, or bilateral ON. Forty-one of the patients were found to have developed additional symptoms and signs of MS according to the criteria of Millar, ${ }^{15}$ the remaining 59 patients showing no further evidence of demyelination. All the patients were subdivided according to the category of their preceding ON; in the MS group 17 had unilateral, 11 recurrent, and 13 bilateral $\mathrm{ON}$, while the corresponding figures for the 59 patients without evidence of MS were 39, 9, and 11 respectively. Serum samples were taken from all patients when reviewed. Control sera were from healthy blood donors matched for sex and age ( \pm 2 years).

Series B-During 1973 and 1974, 17 patients were admitted to hospital in the acute phase of $\mathrm{ON}$; nine had unilateral, two bilateral, and six recurrent $O N$. None of the patients in either series $A$ or series $B$ had symptoms or signs of MS at the time of or before their initial attack of ON. At the time of writing only one patient in series B had developed such symptoms and signs.

Laboratory and statistical methods-Specimens were stored at $-20 \mathrm{C}$ and tested under code by indirect immunofluorescence to detect and titrate measles-virus-specific IgG. ${ }^{16}$ Measles-virus-infected $\mathrm{HEp}_{2}$ tissue-culture cells were used as antigen and the conjugate was fluorescein-labelled antihuman IgG. Antibody titres were expressed as reciprocals, the geometric mean titres (GMTs) being calculated for each group of patients and controls. Since the logarithms of the antibody titres did not form a normal distribution in any of the groups studied, the sign test was used to assess the significance of the differences found when matched pairs of antibody titres were compared. The exact probability method was used to assess the significance of differences in assessing the findings in series B. Cell counts and protein tests were made on the CSF specimens before storage.

\section{Results}

SERIES A

The most striking finding was that the GMTs of measles-virusspecific IgG in all three groups of patients with ON who subsequently developed MS were higher than in either the controls or the patients with uncomplicated $\mathrm{ON}$ (see table). The only statistically significant difference, however, was found between the 41 patients who developed MS (GMT 244.1) and their matched controls (GMT 116.1). In the comparison of matched pairs of titres there were 6 ties, 26 pairs in which the titres of the study group exceeded those of the control group, and 9 pairs with higher levels in the controls $\left(\chi^{2}=8.257 ; \mathrm{DF}=1\right.$; $\mathrm{P}<0.01)$.

In the 59 patients with uncomplicated $O N$ and their matched controls the overall GMTs of the antibody were similar (137.3 and 
132.0 respectively). In the nine patients with recurrent uncomplicated $\mathrm{ON}$, however, the GMT of the antibody was higher than in their matched controls and comparable to that of the MS groups. Because of the small numbers no statistically significant difference was found.

When the titres of the 41 patients with MS were compared with those of 41 of the 59 patients with uncomplicated ON-matched for sex and as closely as possible for age ( \pm 4 years)-significantly higher levels were found in the MS group (GMT 244.1 compared with GMT 120.0). In this comparison there were 6 ties, 26 pairs in which the titre of the patient with MS exceeded that of the patient with ON, and 9 pairs in which the titre of the patient with ON exceeded that of the patient with $M S\left(\chi^{2}=8.257 ; \mathrm{DF}=1 ; \mathrm{P}<0.01\right)$.

Reciprocals of geometric mean titres of measles-virus-specific $\operatorname{Ig} G$ in serum of various groups of patients

\begin{tabular}{|c|c|c|c|c|}
\hline \multirow{2}{*}{ Clinical group } & \multicolumn{2}{|c|}{ Geometric mean titres } & \multirow{2}{*}{$\begin{array}{c}\text { No of } \\
\text { patients in } \\
\text { each group }\end{array}$} & \multirow{2}{*}{$\mathbf{P}$} \\
\hline & Patients & Controls & & \\
\hline $\begin{array}{l}\text { Unilateral ON.. } \\
\text { Recurrent ON .: } \\
\text { Bilateral ON .. }\end{array}$ & $\begin{array}{r}138 \cdot 8 \\
201 \cdot 6 \\
96 \cdot 6\end{array}$ & $\begin{array}{r}162.9 \\
93.3 \\
79.9\end{array}$ & $\begin{array}{r}39 \\
9 \\
11\end{array}$ & $\begin{array}{l}\text { NS } \\
\text { NS } \\
\text { NS }\end{array}$ \\
\hline Total & $137 \cdot 3$ & $132 \cdot 0$ & 59 & NS \\
\hline $\begin{array}{l}\text { Unilateral ON } \rightarrow \text { MS } \ldots \\
\text { Recurrent ON } \rightarrow \text { MS } \ldots \\
\text { Bilateral ON } \rightarrow \text { MS } \quad \ldots\end{array}$ & $\begin{array}{l}212 \cdot 8 \\
300 \cdot 4 \\
245 \cdot 1\end{array}$ & $\begin{array}{l}110 \cdot 9 \\
124 \cdot 4 \\
116 \cdot 2\end{array}$ & $\begin{array}{l}17 \\
11 \\
13\end{array}$ & $\begin{array}{l}\text { NS } \\
\text { NS } \\
\text { NS }\end{array}$ \\
\hline Total & $244 \cdot 1$ & $116 \cdot 1$ & 41 & $<0.01$ \\
\hline
\end{tabular}

NS $=$ Not significant.

\section{SERIES B}

The CSF of eight of the 17 patients seen during an acute attack of ON contained more than $5 \times 10^{6}$ lymphocytes/l, with an associated paretic Lange curve in four. Measles-virus-specific IgG was detected in the CSF of nine of the 17 patients, and, though the numbers were small, the titres were slightly higher in those with the higher lymphocyte count (fig 1). The titres of serum antibody tended to be higher in those patients with antibody detectable in the CSF (GMT 435.4 compared with GMT 174.5) (fig 2). This relationship of high serum titres with detectable CSF antibody was statistically significant (P (two-tailed) $=0.0023$, exact probability). The antibody was detected in the CSF of three of the nine patients with unilateral ON and six of the eight with bilateral or recurrent lesions.

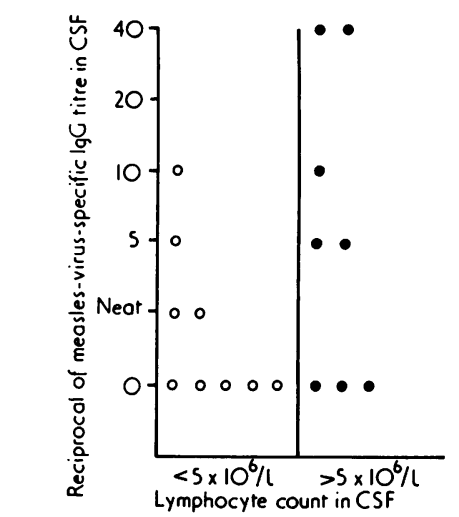

FIG 1-Titres of measles-virus-specific IgG in CSF in relation to lymphocyte counts.

\section{Discussion}

These results show that patients with MS known to occur after a definite episode of $O N$ have significantly higher titres of measles-virus-specific IgG in their serum than either patients with ON who do not develop MS or normal controls.

In contrast to our patients, those of Nikoskelainen et $a l^{8}$ were in a clinically active phase of ON when their sera were obtained. Their serological study included a follow-up examination of later specimens and showed that viral antibodies were usually highly

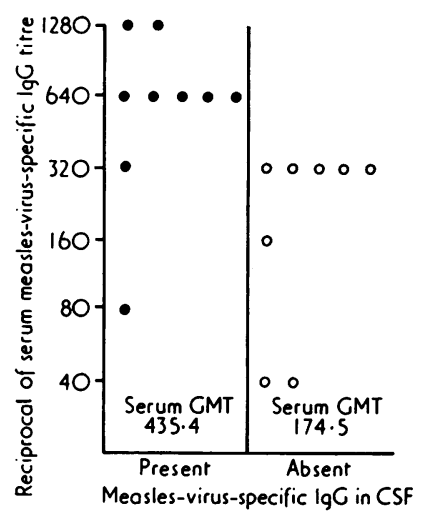

FIG 2-Relationship between presence of measles-virus-specific IgG in CSF and reciprocals of corresponding serum titres. $\mathrm{GMT}=$ Geometric mean titre.

stable and that a relapse did not usually cause an alteration in titre. They did show significantly higher measles antibody titres in patients with ON of unknown cause than in control groups of normal people and neurological patients when Student's $t$ test was employed, but the use of the sign test to compare the groups did not confirm this difference, partly due to small numbers.

Arnason $e t a l^{17}$ found no difference in measles antibody titres when examining sera from 30 patients with ON, 56 with MS, and 1000 control blood donors, though the titres of both neutralising and haemagglutinin-inhibiting antibodies were low, indicating relatively insensitive test systems. They did, however, find a significant increase in measles antibodies in patients bearing the histocompatibility antigen HLA-3 whether they had MS or not, and suggested that the small increase in measles antibody levels in MS may reflect an increased prevalence of HLA-3 in these people rather than a direct association. They found an increased prevalence of this antigen in a series of 56 patients with MS but not in a series of 30 patients with ON. An increase in the 1.3 phenotype was present in both groups, however, suggesting a link between them.

There are several possible explanations for the higher titre of measles antibody in patients with MS compared with those with uncomplicated ON. The two groups may differ in the prevalence of HLA-3, the level of measles-virus-specific IgG may be related to the extent of demyelination in the past, or the measles IgG may become raised during the acute attack of $\mathrm{ON}$, may fall to normal levels during convalescence, and may later become raised with the development of MS.

In our clinical study ${ }^{3}$ we showed that there is a high risk for the development of MS after an attack of ON and feel, therefore, that all our cases of ON represented early manifestations of MS. As we have repeatedly shown slightly increased levels of measlesvirus-specific IgG in the seruni of patients with MS we think it unlikely that the differences in antibody titres in the present study groups were simply due to differences in the prevalences of histocompatibility types. It is more probable that the measles antibody titres were related to the extent of demyelination that had occurred in the central nervous system. Measles IgG levels were higher in the serum of the patients with recurrent uncomplicated $\mathrm{ON}$ than in those with unilateral uncomplicated ON. Our study of a few patients with acute attacks of ON provides some evidence that increased production of measles antibody in both serum and CSF might in some way reflect a more extensive lesion in the central nervous system. We have shown a statistically significant relationship between the presence of measles IgG in CSF and high serum titres; also higher titres of measles IgG in CSF appear to be associated with higher numbers of lymphocytes. We previously reported an apparent correlation between the presence of virus-specific IgG in CSF and the titre of the same antibody in serum in MS. ${ }^{13}$

The present findings suggest that it would be worthwhile to 
carry out serial estimations in sera and possibly in CSF from patients with $\mathrm{ON}$ and with other initial symptoms suggestive of MS to elucidate the relationship of changes in antibody titres to the clinical progression of the disease.

W M Hutchinson was in receipt of a clinical research fellowship from the Royal Victoria Hospital, Belfast. We thank the Medical Research Council for financial support to the department of microbiology and immunobiology, the Queen's University of Belfast, where the antibody estimations were made. We also thank the consultant neurologists and ophthalmologists who kindly allowed W M Hutchinson to examine patients under their care, and Dr J D Merrett, department of medical statistics, who gave valuable help with the statistical analyses. We are grateful to Dr Sheila V C Balmer, of the Northern Ireland Blood Transfusion Service, for making available sera from normal healthy adults. Mrs Patricia McCullough gave excellent technical help.

\section{References}

1 Leibowitz, U, Alter, M, and Halpern, L, Archives of Neurology, 1966, 14, 459.
${ }^{2}$ McAlpine, D, in Multiple Sclerosis: A Reappraisal, ed D McAlpine, C E Lumsden, and E D Acheson, p 148. Edinburgh and London, Churchill Livingstone.

${ }^{3}$ Hutchinson, W M, submitted for publication.

4 Adams, J M, and Imagawa, D T, Proceedings of the Society for Experimental Biology and Medicine, 1962, 111, 562.

${ }^{5}$ Brody, J A, et al, Neurology, 1972, 22, 492.

${ }^{6}$ Brown, P, et al, Proceedings of the Society for Experimental Biology and Medicine, 1971, 137, 956.

7 Salmi, A A, Norrby, E, and Panelius, M, Infection and Immunity, 1972 $6,248$.

${ }^{8}$ Nikoskelainen, E, et al, Acta Neurologica Scandinavica, 1975, 51, 333.

${ }^{9}$ Link, H, Norrby, E, and Olsson, J-E, New England fournal of Medicine, $1973,289,1103$.

10 Link, H, and Müller, R, Archives of Neurology, 1971, 25, 326.

${ }_{11}$ Nikoskelainen, E, et al, Acta Neurologica Scandinavica, 1975, 51, 347.

12 Haire, M, Fraser, K B, and Millar, J H D, British Medical fournal, 1973 3, 612 .

${ }^{13}$ Haire, M, Fraser, K B, and Millar, J H D, Clinical and Experimental Immunology, 1973, 14, 409 .

${ }^{14}$ Haire, M, Millar, J H D, and Merrett, J D, British Medical fournal, 1974, 4, 192.

${ }^{15}$ Millar, J H D, Multiple Sclerosis: A Disease Acquired in Childhood. Springfield, Illinois, Thomas, 1971.

${ }^{16}$ Haire, M, Adair, B McC, and Fraser, $\mathrm{K} \mathrm{B}$, Clinical and Experimental Immunology, 1973, 14, 409.

17 Arnason, B G W, et al, fournal of the Neurological Sciences, 1974, 22, 419.

\title{
Climate and painful crisis of sickle-cell disease in Jamaica
}

\author{
ALVA M REDWOOD, EVADNE M WILLIAMS, PATRICIA DESAI, GRAHAM R SERJEANT
}

British Medical fournal, 1976, 1, 66-68

\section{Summary}

In a 10-year retrospective study a close correlation was found between low temperatures and hospital admissions for severe painful crises of sickle-cell disease.

\section{Introduction}

The pathogenesis of the painful crisis of sickle-cell disease is often obscure, though it may be precipitated by infection, especially malaria, in the last trimester of pregnancy and the immediate post-partum period, and by acidosis after ammonium chloride ingestion. Climate may also be important, and there is a widely held impression that painful crises are more frequent in cold, damp periods of the year. ${ }^{1-4}$ Diggs $^{1}$ noted this in Memphis, yet prospective studies over 14 years in one case and two years in 37 cases failed to show a seasonal relationship in respect of bone pain. ${ }^{5}$ No seasonal pattern was apparent in hospital admissions of children with sickle-cell crises in Chicago, ${ }^{6}$ yet a five-year retrospective study in Buffalo ${ }^{7}$ showed that admissions were more frequent in winter. The evidence is therefore conflicting, and we present here the results of a retrospective study of the seasonal incidence of painful crises in Jamaica.

MRC Laboratories (Jamaica), University of the West Indies, Kingston, Jamaica

ALVA M REDWOOD, $\mathrm{MB}$, BS, medical student on elective attachment (now house physician at George V Memorial Sanatorium, Kingston)

EVADNE $M$ WILLIAMS, $M B$, BS, medical student on elective attachment (now house physician at Spanish Town Hospital)

PATRICIA DESAI, BA, statistical assistant

GRAHAM R SERJEANT, MD, MRCP, director of unit

\section{Patients and methods}

The patients attended the adult and paediatric sickle-cell clinics of the University Hospital of the West Indies, and all fulfilled the diagnostic criteria for sickle-cell (SS) disease. ${ }^{8}$ A painful crisis was defined as pain in the abdomen, chest, or limbs unexplained on any basis other than SS disease. Juxta-articular areas of limb bones were most commonly affected, and pyrexia and red urine were frequent. Pains associated with pregnancy or secondary to an obvious disease such as pneumonia were excluded since such episodes might confuse an assessment of the aetiological role of climate.

Records of painful crises were collected from three sources. Details of hospital admissions for painful crises in the 10-year period 1964-73 were obtained from the hospital notes of all patients registered at the sickle-cell clinic. Details of attendances in the casualty department during the five years 1969-73 were obtained from the casualty notes, patients subsequently admitted for severe pain being excluded. Review of the sickle-cell clinic notes for the same five-year period yielded episodes of mild pain treated at home.

"Maximum" temperature ( $1 \mathrm{pm})$, "minimum" temperature (7 am), and rainfall, recorded at a meteorological unit in central Kingston, were expressed as mean monthly values for the years 1964-73.

\section{Results}

Mean monthly minimum temperatures, rainfall, and number of painful crises are given in the table. Maximum temperatures were some $8-9$ C higher than minimum temperatures, and a steady rise in minimum temperature occurred from $21^{\circ} \mathrm{C}$ in January to about $24^{\circ} \mathrm{C}$ in July. Rainfall varied, but December to April was generally dry, rain increased during May to September, and the rainy season occurred during October and November.

Yearly hospital admissions for severe painful crises increased over the 10-year period, from 4 in 1964 to 28 in 1973, reflecting at least in part an increase in overall hospital admissions. Admissions for crisis in any single month varied from 0 to 6 . Painful crises as documented in all three sources followed similar seasonal patterns, with a higher incidence in the winter than in the summer. Since painful crises necessitating hospital admission were of a more uniform severity and also allowed exclusion of other precipitating factors, these crises were used in examining the relationship between crises and climatic 